\section{CIÊNCIA E TEATRO COMO OBJETO DE PESQUISA}

\author{
Carla Almeida, Luiz Bento, Gabriela Jardim, \\ Maíra Freire, Luís Amorim, Marina Ramalho
}

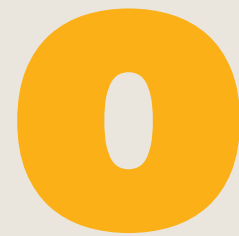

diálogo entre a ciência e o teatro é antigo. Com forte presença na literatura, a ciência vem inspirando uma série de dramaturgos ao longo da história. Desde Dr. Fausto, de fins do século XVI, até a contemporânea Copenhagen, peças sobre personagens, temas e acontecimentos do universo científico já ganharam os palcos de diversos teatros. O fato é que a vida de cientistas, seus dilemas éticos e morais, suas descobertas e os seus impactos são um prato cheio para a dramaturgia e, por meio dela, tem sido possível compartilhar parte dessa história com um grupo grande de pessoas que vão ao teatro.

Mais recentemente, a divulgação científica tem lançado mão, de forma cada vez mais recorrente e diversa, de elementos teatrais em suas iniciativas práticas. Nesse contexto, vários argumentos têm sido mobilizados em prol da união entre ciência e teatro. Os divulgadores entusiastas dessa parceria e alguns autores que se debruçaram sobre o tema argumentam que, por meio das artes cênicas, é possível: mobilizar sentidos e emoções [1]; abordar temas complexos de forma envolvente [2,3]; tratar aspectos controversos, éticos e políticos da ciência; explorar o lado humano dos cientistas [4]; desconstruir a suposta frieza da atividade científica e aproximá-la do público [5]; e, por fim, estimular a reflexão sobre o avanço do conhecimento humano e suas implicações [6].

Com esses e outros objetivos, museus e centros de ciência têm contemplado a interface ciência e teatro em suas programações. Em levantamento recente, Medeiros e Marandino [7] identificaram, no Brasil, 14 museus de ciência que realizam atividades teatrais, incluindo desde a contação de história até o teatro mais convencional, passando por esquetes, circo, dança, shows de ciência, repentes, entre outras. Independentemente do tipo de atividade, o que se observa em relação ao teatro nesses espaços é uma diversidade enorme de experiências. Em alguns museus as atividades teatrais são esporádicas, enquanto em outros integram a programação permanente; uns contam com equipes amadoras, outros, com profissionais; uns se baseiam em dramaturgia já existente, outros criam seus próprios textos e espetáculos.

Para além dos museus de ciências, há grupos universitários e companhias independentes trabalhando na interseção entre ciência e teatro, com bagagens e propósitos diversos. Especialmente para esses grupos, o evento Ciência em Cena tem se consolidado como um espaço importante de troca de experiências sobre a interação entre esses dois campos. O evento, criado em 2007 pelo Núcleo
Ouroboros de Divulgação Científica - inserido no Departamento de Química da Universidade Federal de São Carlos (UFScar) -, chegou em 2017 à sua décima primeira edição. Realizado entre 13 e 17 de agosto do ano passado, o XI Ciência em Cena contou com a apresentação de 17 peças teatrais, a realização de 10 oficinas e a participação de cerca de 200 pessoas [8].

Se por um lado as iniciativas unindo ciência e teatro são cada vez mais numerosas na divulgação científica, por outro, a literatura acadêmica sobre o tema ainda é escassa e, em grande medida, estrangeira. Isso significa que conhecemos pouco o conjunto do que está sendo feito no campo e sabemos menos ainda sobre como o teatro tem de fato contribuído para a divulgação científica. A fim de compreender melhor as diversas facetas da interface ciência e teatro, um grupo formado por divulgadores da ciência e pesquisadores da área do Museu Ciência e Vida/Fundação Cecierj (Centro de Educação a Distância do Estado do Rio de Janeiro) e do Museu da Vida/Fiocruz - dentre os quais estão os autores deste artigo - iniciou, em fins de 2014, um projeto de pesquisa sobre o tema. A proposta do grupo é analisar uma série de experiências teatrais, especialmente em museus de ciências, com o intuito de conhecer os públicos dessas atividades e seus hábitos culturais; entender como recebem as atividades teatrais oferecidas por essas instituições e os fatores que interferem nessa recepção; e verificar o diferencial do teatro em meio a outras estratégias de divulgação científica. Também estamos interessados em atestar o potencial da interface ciência e teatro para aquisição de capital cultural.

\section{CIÊNCIA E ARTE NO MUSEU CIÊNCIA E VIDA E NO MUSEU DA VIDA O} projeto aqui apresentado une profissionais e pesquisadores de dois museus que compartilham características comuns: são espaços interativos de divulgação e engajamento na ciência, voltados ao público amplo, escolar e espontâneo; estão situados em regiōes desprivilegiadas, onde moram indivíduos com acesso escasso a serviços básicos e a opções de cultura e entretenimento; e reconhecem a importância e investem, cada um a seu modo, em atividades de lazer educativo e cultural, como veremos a seguir.

O Museu Ciência e Vida é um centro interativo de ciências localizado em Duque de Caxias, na Baixada Fluminense, região com um dos índices sociais e educacionais mais baixos do estado do Rio de Janeiro e carente de equipamentos culturais e opções de lazer. Aberto ao público em julho de 2010, o museu, que integra o programa de divulgação científica da Fundação Cecierj, é fruto de uma política pública voltada às necessidades locais, tendo sido pensado e planejado para suprir, em parte, a falta de oferta cultural na região. Dentre as atividades desenvolvidas pelo museu, destacam-se as exposições, sessões de planetário, oficinas interativas e encontros com cientistas, voltadas ao público escolar e espontâneo. O centro também promove exibições de filmes e apresentações musicais, buscando se consolidar como um espaço de entretenimento para os moradores da Baixada Fluminense. Além disso, 
visando diversificar sua programação e ao mesmo tempo oferecer novas opções de lazer cultural, o Museu Ciência e Vida, seguindo a tendência de diversos espaços de divulgação científica, tem investido em iniciativas que mesclam ciência e arte, mais especificamente ciência e teatro. Entre outubro de 2014 e fevereiro de 2015, promoveu duas atividades teatrais - a peça Rossum e Asimov e a visita teatralizada à exposição "A herança da Terra: salvar o planeta do Pequeno Príncipe" -, sobre as quais falaremos mais adiante. E desde 2015 realiza esporadicamente o evento "Domingo Espacial", atividade lúdica e interativa sobre temas astronômicos que ocupa diversos espaços do museu com história, ciência e artes cênicas [9].

Inaugurado em 1999 no campus de Manguinhos da Fiocruz, o Museu da Vida se propõe a ser um espaço de integração, no qual ciência, saúde, história e cultura se unem para dialogar com a sociedade, por meio de exposições permanentes e temporárias, atividades interativas, produtos multimídia e manifestações artísticas, com destaque para as artes cênicas. Um dos projetos permanentes do museu, que se materializa em dois espaços físicos - Tenda da Ciência Virgínia Shall e Epidaurinho -, o Ciência em Cena foi concebido com o propósito de desenvolver pesquisa sobre ciência e arte e atividades de divulgação e discussão de temáticas científicas, a partir de diferentes linguagens artísticas [10]. Com uma equipe multidisciplinar que inclui profissionais das artes cênicas, o Ciência em Cena apresenta ao público do Museu da Vida produções teatrais com motes científicos, em diferentes formatos. Localizado em meio a comunidades carentes, em uma região com índice de desenvolvimento humano (IDH) baixo e com poucas opções de lazer cultural, o museu torna-se, muitas vezes, um espaço não apenas de divulgação e educação em ciência, mas também de primeiro contato com as artes cênicas - dessa forma, a equipe do Ciência em Cena desempenha ainda o papel de formador de plateia. Em seu repertório, constam cerca de vinte produções, entre peças, esquetes, saraus científicos e leituras dramatizadas. Após serem apresentadas no museu, algumas delas itineram por outros espaços, ampliando seu alcance. Duas peças desse repertório foram objeto de pesquisa do nosso grupo e serão descritas na próxima seção.

No âmbito acadêmico, as iniciativas voltadas ao estudo das interações entre ciência e arte têm sido mais irregulares nos museus mencionados. No que tange ao Museu Ciência e Vida, o nosso projeto foi o primeiro a propor um olhar investigativo sobre o tema de maneira mais aprofundada. No Museu da Vida, existe um movimento de discussão e reflexão constante sobre a temática ciência e arte, não apenas no Ciência em Cena. $\mathrm{O}$ assunto tem motivado debates em uma série de eventos promovidos pelo museu e sua experiência tem sido compartilhada de diversas formas - em encontros internos e externos, publicações e apresentações de trabalho.
Em apresentação no XIV Congresso da Rede de Popularização da Ciência e da Tecnologia na América Latina e no Caribe (RedPop), realizado em maio de 2015, em Medelín, Colômbia, cujo tema central foi arte, ciência e tecnologia, Leticia Guimarães - integrante do Ciência em Cena - e colegas $[11,12]$ apresentaram uma reflexão sobre o papel do teatro em museus de ciência, a partir da montagem do espetáculo Aprendiz de feiticeiro no Museu da Vida. Para os autores, a peça e o debate promovido após a apresentação desempenharam o duplo papel de popularização da ciência e de democratização da arte.

Em termos de pesquisas acadêmicas acerca das interações entre ciência e teatro, mais escassas, destaca-se o trabalho de Thelma Lopes, que coordenou o Ciência em Cena entre 2002 e 2010 e que hoje integra a equipe de divulgação científica da Fundação Cecierj. Lopes analisou no mestrado três versões da peça $A$ vida de Galileu, de Bertolt Brecht [13], e no doutorado investigou o papel da interface ciência e teatro na educação científica e o potencial da linguagem teatral na construção de imagens menos estereotipadas do cientista e artista [14], trabalhos que renderam contribuições para a literatura na área.

A pesquisa sobre o tema "ciência e arte" vem se consolidando no Núcleo de Estudos da Divulgação Científica (NEDC) do Museu da Vida. Já foram desenvolvidos estudos sobre a presença da ciência no cinema [15], especificamente em curtas de animação [16], na música [17] e na literatura de cordel [18], por exemplo. Tais trabalhos têm ajudado a identificar e a mapear a inserção da ciência e de temas correlatos em manifestações artísticas, especialmente no contexto brasileiro. Por outro lado, analisam a representação da ciência e dos cientistas nessas expressões culturais, nos ajudando a compreender as percepçōes sobre a ciência que circulam na sociedade. Entre outras iniciativas do NEDC nessa seara, cabe destacar a sua participação na organização de um suplemento da revista História, Ciências, Saúde-Manguinhos sobre ciência e arte [19] e do simpósio "Ciência e Arte", realizado na Fiocruz em outubro de 2006, que teve como um dos frutos a publicação Memórias do Simpósio Ciência e Arte 2006 [20]. No que tange ao teatro especificamente, sua interação com a ciência é um tema de interesse recente no NEDC, sendo este projeto o primeiro passo para uma análise mais sistemática sobre o assunto que o núcleo pretende empreender nos próximos anos (ver os resultados adiante).

ESTUDOS DE CASO Entre outubro de 2014 e dezembro de 2016, estudamos quatro atividades teatrais realizadas em museus de ciências: a peça Rossum e Asimov e a visita teatralizada à exposição "A herança da Terra: salvar o planeta do Pequeno Príncipe", no Museu Ciência e Vida; e as peças $O$ rapaz da rabeca e a moça Rebeca e $A$ vida de Galileu, no Museu da Vida. As quatro ativida- 


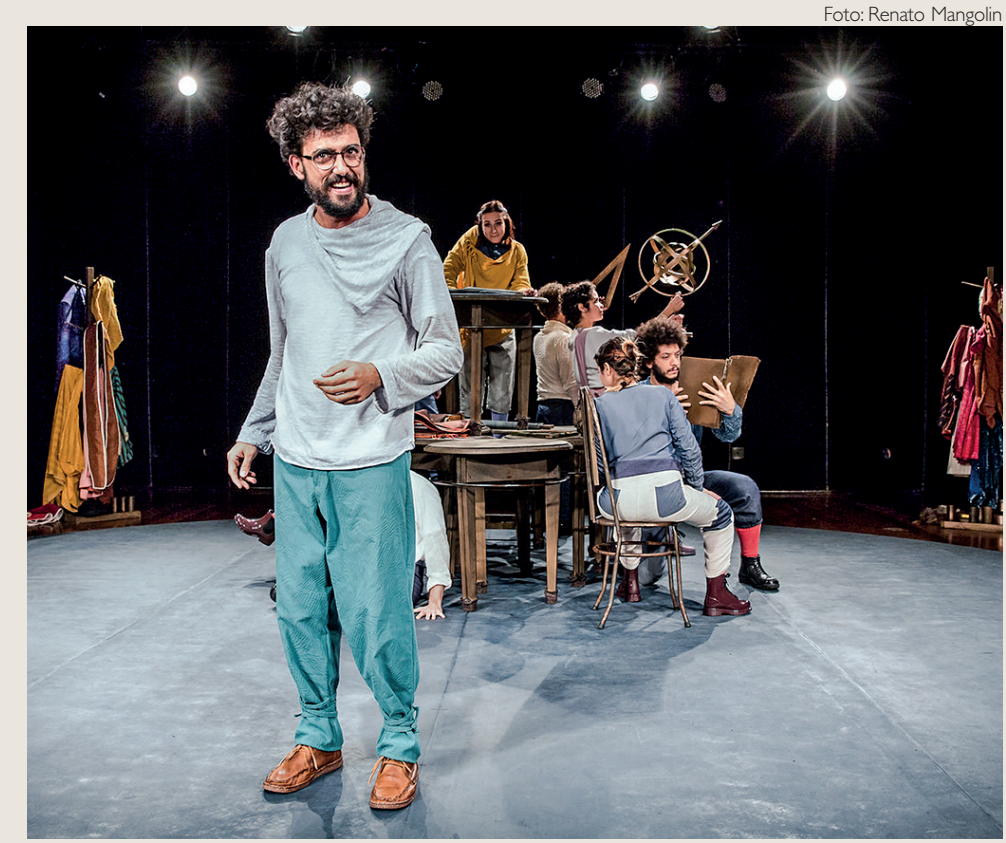

Cenas das peças Vida de Galileu (acima, canto superior esquerdo),

0 rapaz da rabeca e a moça Rebeca (acima, canto superior direito) e imagem da visita teatralizada à exposição "Herança da Terra" (ao lado)

des possuem caráteres bastante distintos, e foram realizadas em diferentes condiçōes. Rossum e Asimov é uma peça infantil sobre robótica, que foi encenada no auditório do Museu Ciência e Vida, tendo como cenário um laboratório onde dois "palhaços-cientistas" trabalham na construção de máquinas mirabolantes. A visita teatralizada ocorreu no espaço da exposição "A herança da Terra...”, que tratou da obra do autor francês Antoine de Saint-Exupéry. Nessa atividade, um ator fazia o papel do escritor, que recitava trechos de seus livros e cartas e percorria e comentava os painéis da mostra com um grupo de visitantes. $\mathrm{O}$ museu, que não conta com uma equipe dedicada ao teatro e não possui atividades teatrais em sua programação permanente, contratou atores para ambas as iniciativas - no caso de Rossum e Asimov, a peça foi construída em conjunto com a direção do museu.

Adaptada da obra do cordelista cearense José Mapurunga, o espetáculo $O$ rapaz da rabeca... aborda o tema da Aids, com foco na prevenção e no preconceito, por meio de uma história de amor proibido à la Romeu e Julieta. Concebida, dirigida e produzida pela equipe do Ciência em Cena, a peça é encenada no formato teatro de arena, tendo a música - tocada ao vivo - e o humor como elementos marcantes, e voltada especialmente ao público adolescente/jovem. Por fim, $A$ vida de Galileu, texto clássico de Bertolt Brecht, que, como indica o título, conta a história do físico italiano Galileu Galilei, teve seu texto adaptado para encenação no museu. Para a sua montagem, foram contratados
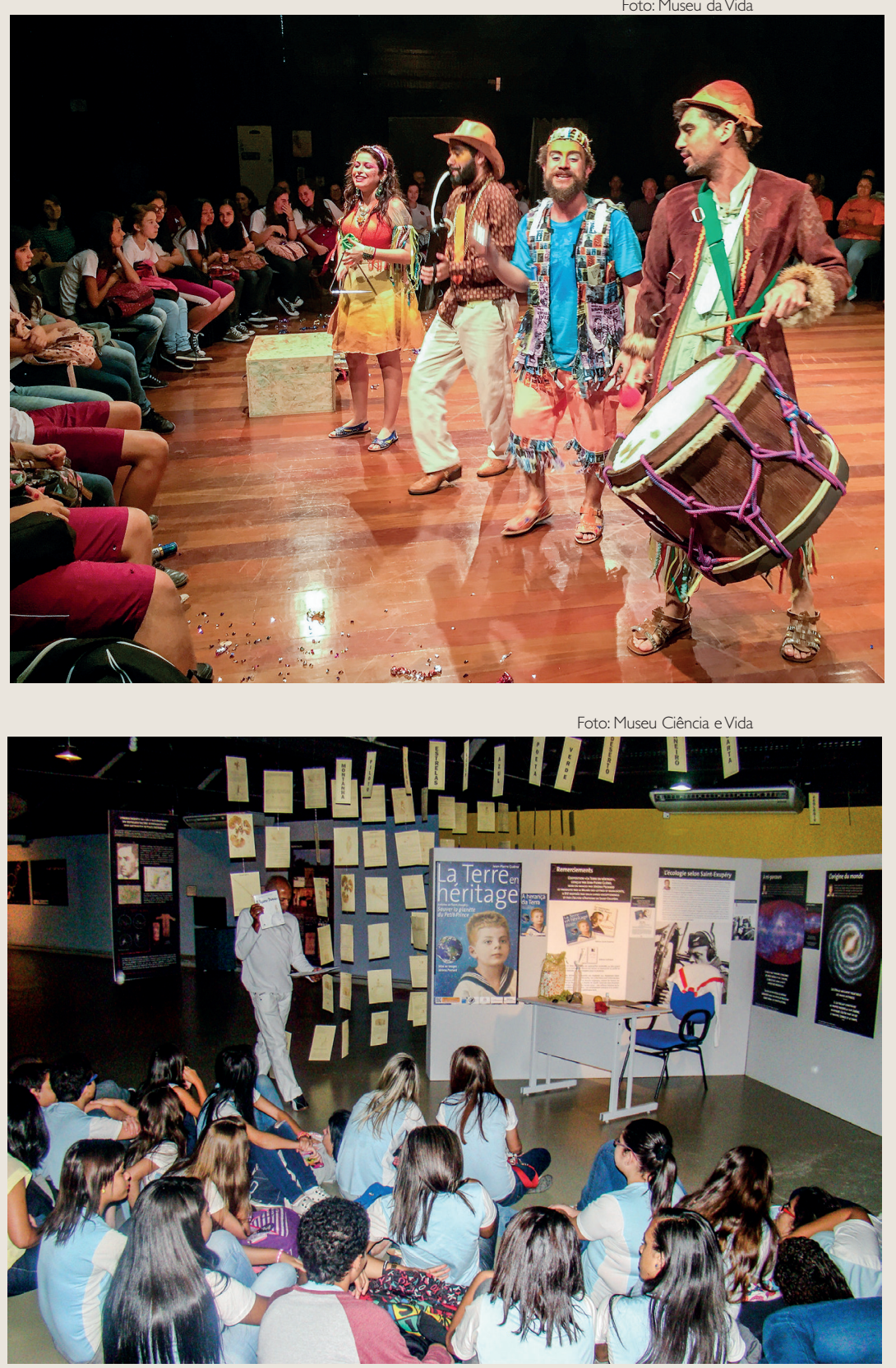

profissionais externos - diretor, técnicos e elenco -, além da participação de integrantes do Ciência em Cena.

O estudo das atividades descritas envolveu diferentes procedimentos e instrumentos metodológicos, de caráter quantitativo e qualitativo. Em geral, seguimos as seguintes etapas: conversas com a produção (diretores e atores); familiarização com o espetáculo (leitura dos textos, acompanhamento dos ensaios e assistência da peça); construção dos instrumentos de coleta de dados (ficha de observação, questionários, entrevistas pós-espetáculo); realização de testes e ajustes; aplicação dos instrumentos; e, por fim, análise - etapa que 
Tabela 1. Informações acerca das atividades que foram objeto deste estudo e corpus de análise

\begin{tabular}{|c|c|c|c|c|}
\hline Atividade & Local & Período analisado & Público consultado & Corpus de análise \\
\hline Peça Rossum e Asimov & $\begin{array}{l}\text { Museu Ciência e Vida/ } \\
\text { Fundação } 2015 \text { Cecierj }\end{array}$ & out. e nov. 2014; jan. & Público escolar & 55 questionários \\
\hline $\begin{array}{l}\text { Visita teatralizada à exposição } \\
\text { "A Herança da Terra: salvar o } \\
\text { planeta do Pequeno Príncipe" }\end{array}$ & $\begin{array}{l}\text { Museu Ciência e Vida/ } \\
\text { Fundaçãa } 2015 \text { Cecierj }\end{array}$ & nov. 2014; jan. e fev. & $\begin{array}{l}\text { Público escolar e } \\
\text { público espontâneo }\end{array}$ & $\begin{array}{l}76 \text { questionários; } \\
10 \text { entrevistas com } \\
\text { o público }\end{array}$ \\
\hline $\begin{array}{l}\text { Peça } 0 \text { rapaz da rabeca } \\
\text { e a moça Rebeca }\end{array}$ & Museu da Vida/ Fiocruz & jun., nov. e dez. 2016 & $\begin{array}{l}\text { Público escolar e } \\
\text { público espontâneo }\end{array}$ & $\begin{array}{l}346 \text { questionários; } 9 \text { fichas } \\
\text { de observação; } 5 \text { debates; } \\
2 \text { entrevistas com o público }\end{array}$ \\
\hline Peça A vida de Galileu & Museu da Vida/ Fiocruz & nov. e dez. 2016 & $\begin{array}{l}\text { Público escolar e } \\
\text { público espontâneo }\end{array}$ & $\begin{array}{l}381 \text { questionários; } 9 \text { fichas } \\
\text { observaçáa; } 2 \text { entrevistas } \\
\text { com o público; } 7 \text { entrevistas } \\
\text { com professores }\end{array}$ \\
\hline
\end{tabular}

ainda se encontra em desenvolvimento para os espetáculos encenados no Museu da Vida.

Cada procedimento metodológico nos permitiu observar aspectos diferentes da recepção da peça. Por meio da ficha de observação, registramos as expectativas dos visitantes logo antes do início da peça, suas reações imediatas durante o espetáculo e as condições de recepção. Com o questionário, verificamos o grau de satisfação dos espectadores com a peça, os pontos altos e baixos do espetáculo de acordo com sua avaliação e suas visões sobre os principais temas e mensagens da peça. Buscamos também compreender como diferentes fatores - sociodemográficos, hábitos culturais, entre outros - contribuíram para sua recepção do espetáculo. Por fim, as entrevistas realizadas após as apresentações nos permitiram explorar o contexto da visita, as motivações dos espectadores e seus conhecimentos prévios sobre a obra e os temas abordados. Essas entrevistas possibilitaram ainda uma reflexão mais profunda sobre o espetáculo por parte do espectador consultado.

Para a análise estatística dos dados quantitativos coletados, utilizamos o software SPSS - após a tabulação de todos os questionários em planilhas de Excel. Já para analisar os dados qualitativos e discutir os resultados dos nossos estudos, nos embasamos em referenciais teóricos de distintos campos, particularmente da divulgação científica, dos estudos de visitante, das ciências sociais (em especial Pièrre Bourdieu e seu conceito de capital cultural) e dos estudos de recepção (em particular Jesús Martín-Barbero e seu conceito de mediações). Buscamos também conceitos das teorias do teatro; utilizamos especialmente uma revisão dos estudos no campo de autoria de Patrice Pavis, além de considerações sobre a recepção teatral de Marco de Marinis e Flávio Desgranges.

RESULTADOS PRELIMINARES Analisados isoladamente, os resultados dos estudos de caso não podem ser extrapolados para todo o universo das iniciativas teatrais com mote científico - as atividades são muito diversas, bem como seus propósitos e contextos de recepção. No entanto, quando examinamos conjuntamente nossos dados, podemos fazer algumas constatações mais gerais a respeito da interface ciência e teatro no contexto da divulgação científica - particularmente em museus de ciências - e, a partir delas, começar a responder algumas de nossas perguntas de pesquisa.

Tanto os visitantes do Museu Ciência e Vida quanto do Museu da Vida - ambos localizados em regióes com alto índice de violência e poucas opções de lazer cultural, habitadas por população em geral de baixa renda e baixa escolaridade - têm alguma familiaridade com e certo interesse por teatro. No entanto, por diversos motivos, são frequentadores eventuais desses espaços. Em outras palavras, poucos têm o teatro como um hábito cultural enraizado.

Muitas vezes os visitantes - especialmente aqueles que visitam o museu em grupos escolares - vão ao museu sem saber que terão uma experiência teatral e, nesses casos, o teatro emerge, em geral, como uma surpresa positiva. Por outro lado, isso significa que raramente existe uma preparação prévia para a ida ao teatro, como corroboram Rosseto [21] e Ferreira [22]. É comum, portanto, que os visitantes saibam pouco sobre a obra a que vão assistir, seu contexto histórico e o tema que aborda. Somando isto ao fato de conhecerem pouco o universo teatral, pode-se dizer que a experiência com o teatro que os visitantes têm no museu é, em geral, descontextualizada em diversos níveis. Isto, por sua vez, pode ser um obstáculo para que essa experiência seja plena - o que De Marinis [23] chama de "interação significante" - e atinja seu potencial máximo de aproveitamento e, em última instância, que os objetivos da produção/direção sejam plenamente alcançados.

Ainda assim, podemos dizer que os visitantes ficam, em geral, satisfeitos com a experiência que têm no museu e com a atividade teatral da qual participam. A grande maioria avalia muito bem as peças, valorizando tanto as temáticas abordadas quanto os recursos artísticos explorados - nos nossos estudos de caso, especialmente o humor, a música (no caso específico de $O$ rapaz da rabeca...) e a atuação (sobretudo no caso de $A$ vida de Galileu). Um aspecto enfaticamente elogiado é o "casamento" de temáticas científicas com as artes cênicas, vista por muitos como uma combinação acertada. 
Por outro lado, muitos que conferem nota máxima à peça nos questionários não justificam suas avaliações ou as justificam com elogios simples, tais como: "Ótima!"; "Muito boa!”; "Legal”; "Adorei!". Isso pode ser um indicativo de que os espectadores têm dificuldade de avaliar mais criticamente os espetáculos ou simplesmente que têm pouca motivação para responder o questionário. Observamos também que, quando discorrem mais detalhadamente, os espectadores tendem a focar mais os temas e a trama e menos o acontecimento teatral. Este comportamento pode ser uma consequência da pouca experiência com o teatro. Como defende Desgranges [24], é da experiência que vem o prazer, o gosto pela fruição artística e parte da instrumentalização que o indivíduo deve ter para ler e interpretar o teatro, relacionando-o com sua realidade. Vale destacar, no entanto, que, em alguns casos, visitantes com alguma experiência teatral indicaram notas baixas de satisfação por esperarem uma estrutura teatral completa (cenário, iluminação, figurino, entre outros), o que não foi o caso das atividades realizadas no Museu Ciência e Vida, em especial da visita teatralizada.

No que diz respeito aos objetivos institucionais relativos à montagem das peças nos museus de ciências e às mensagens preferenciais das mesmas, pensadas do ponto de vista da produção/direção, observamos que nem sempre coincidem com a experiência vivenciada e os sentidos construídos pelos espectadores no teatro/ museu. Para embasar essa constatação, daremos um exemplo. Ao propor a encenação de $O$ rapaz da rabeca..., a equipe do Ciência em Cena (Museu da Vida) tinha em mente sobretudo provocar uma reflexão sobre o preconceito que ainda existe em torno da Aids no Brasil. No entanto, a equipe se deparou com um público ávido por informações sobre diferentes aspectos da doença, desde os modos de contágio até as novas formas de tratamento. Isso fez com que o grupo buscasse mais informações sobre o tema e redirecionasse o debate realizado após o espetáculo. Como mostram os estudos de recepção latino-americanos embasados na obra de Martín-Barbero [25], a interpretação de mensagens depende de vários fatores ou mediações, na terminologia de Martín-Barbero - pessoais, culturais e contextuais. Por isso não é surpreendente que espectadores construam sentidos diferentes ao ver o mesmo espetáculo - que, na verdade, nunca é o mesmo. O que não deve ser visto como algo negativo, pelo contrário; só prova que o espectador não está sendo um receptor passivo. Ele é um ser interpretante e produtor de sentidos. Isso nos faz lembrar, portanto, que a produção não detém o controle sobre as mensagens que circulam a partir do espetáculo e de como elas são ou não incorporadas à vida dos espectadores.

CONSIDERAÇÕES FINAIS Neste artigo, contextualizamos as iniciativas de ciência e teatro no campo da divulgação científica, dando destaque para as iniciativas do Museu Ciência e Vida/Fundação Cecierj e do Museu da Vida/Fiocruz; apresentamos nosso projeto de pesquisa e seus objetivos; mostramos os estudos de caso rea- lizados até aqui e compartilhamos alguns dos resultados - ainda preliminares. Tudo o que temos lido, visto e analisado ao longo desse percurso indica que a interação ciência e teatro pode e tem rendido bons frutos para a divulgação da ciência, de diversas formas e em diferentes níveis. Ela tem possibilitado a abordagem de temas sérios e complexos de forma lúdica e envolvente, como pudemos ver, por exemplo, no caso da peça $O$ rapaz da rabeca..., que traz à tona questóes relacionadas à doença e à sexualidade. Por meio dessa atividade, também verificamos que o teatro pode ser um importante veículo de comunicação em saúde.

Nossos estudos de caso e outros trabalhos mostram também que iniciativas teatrais com motes científicos têm permitido o acesso ao teatro a um público pouco familiarizado e com acesso restrito a essa forma de arte, e tem proporcionado a esse público, além de informação, prazer e diversão. Essa associação com prazer e diversão é importante para desenvolver o gosto pelo teatro, para a formação de plateia. Mesmo sem dominar os códigos que permitam uma análise mais profunda do teatro - o que poderíamos chamar de "capital teatral", numa apropriação-adaptação do conceito de capital cultural de Bourdieu -, o espectador pode ser impactado pela experiência estética e sensorial do teatro e isso pode ter um desdobramento significativo na sua vida.

Por outro lado, se o objetivo da aliança entre ciência e teatro é formar indivíduos críticos e engajados e promover a cidadania - proposta ambiciosa que está presente no discurso tanto da divulgação científica quanto das artes cênicas contemporâneas -, talvez não baste oferecer espetáculos a um público pouco preparado para a ida ao teatro e pouco estimulado para pensar criticamente sobre essa experiência. Como indicam os dados de nossos e de outros estudos, o conhecimento prévio sobre a obra e sua temática, assim como o domínio de certos códigos e linguagens, tanto da ciência quanto do teatro, são importantes para uma incursão significativa nesses dois mundos. Precisamos, tanto no Museu Ciência e Vida quanto no Museu da Vida, pensar em como enfrentar concretamente esse desafio, talvez a partir de uma articulação maior entre esses museus e as escolas e famílias que os visitam.

Por fim, cabe dizer que, para quem pesquisa este campo, os desafios parecem ainda maiores. Precisamos lidar com as dificuldades logísticas de se fazer pesquisa em museus, a começar pela sensibilização dos visitantes sobre a importância de estudá-los. Há ainda que se consolidar conceitos, metodologias e procedimentos analíticos de investigação da interação entre ciência e teatro no campo da divulgação científica. Para aqueles grupos de pesquisa que atuam em museus de ciências, também cabe pensar em formas de integrar melhor a teoria e a prática. Se existe uma possibilidade real de aplicação da pesquisa, essa possibilidade deve ser aproveitada. Esta é uma forma concreta de dar retorno do nosso trabalho à sociedade. Por isso estimulamos que um maior número de pessoas se junte a nós no esforço de compreender como o teatro e a ciência podem, juntos, contribuir para a divulgação da ciência. 
Carla Almeida é jornalista, doutora em educação, gestão e difusão em biociências e pesquisadora na área de divulgação científica da Casa de Oswaldo Cruz (Fiocruz), onde integra o Núcleo de Estudos da Divulgação Científica do Museu da Vida. E-mail: almeidacarlafiocruz@gmail.com

Luiz Bento é biólogo, doutor em ecologia e divulgador de ciências da Fundaçāo Cecierj (SECTIDS-RJ).

Gabriela Jardim é bióloga, doutora em zoologia e divulgadora de ciências do Museu Ciência e Vida/Fundação Cecierj.

Maíra Freire é graduada em turismo, mestre em museologia e patrimônio pela Unirio e divulgadora de ciência no Museu Ciência e Vida/Fundação Cecierj.

Luís Amorim é jornalista, mestre em ensino em biociências e saúde e coordenador do Núcleo de Estudos da Divulgação Científica do Museu da Vida, Casa de Oswaldo Cruz (Fiocruz).

Marina Ramalho é jornalista, doutora em educação, gestão e difusão em biociências e pesquisadora em divulgação científica da Casa de Oswaldo Cruz (Fiocruz), onde integra o Núcleo de Estudos da Divulgação Científica do Museu da Vida.

\section{NOTAS E REFERÊNCIAS}

1. Fruguglietti, S. "The theatre, (art) and science: between amazement and applause!", JCOM, 8, 2.2009.

2. Black, D. R.; Goldowsky, A. "Science theater as an interpretive technique in a Science Museum". In: Annual Meeting of the National Association for Research in Science Teaching. 1999.

3. Richards, L. "Teatro, mediadores, cientistas punk e visitas-guiadas: os altos e baixos da interpretação ao vivo no Science Museum de Londres". In: Massarani, L.; Almeida, C. Workshop Sul-Americano \& Escola de Mediação em Museus e Centros Ciência. Rio de Janeiro: Museu da Vida COC Fiocruz. 2008. pp 133-142.

4. Moreira, L. M.; Marandino, M. "O teatro em museus e centros de ciências no Brasil", História, Ciências, Saúde-Manguinhos, 22, supl. 2015. pp 1735-1748.

5. Lopes, T. "'Luz, arte, ciência... ação!" História, Ciências, Saúde-Manguinhos, 12, 2005. pp 401-418.

6. Palma, C. "Arte e ciência no palco", História, Ciências, Saúde-Manguinhos, v.13, supl., pp 233-246. 2006. Disponível em: <http://www.scielo.br/scielo.php?script=sci_arttext\&pi$\mathrm{d}=$ S0104-59702006000500014\&lng=en\&nrm=iso .

7. Moreira, L. M.; Marandino, M., op cit.

8. Para mais informações sobre o evento Ciência em Cena, consultar: Liberato, T. "Tema científico serve de contexto para peças e atrai público leigo". Ciência \& Cultura, 66, 4, pp 63-65. 2014.

9. Desde 2015, o Museu Ciência e Vida passa por dificuldades financeiras que decorrem da crise generalizada do estado do Rio de Janeiro, o que vem afetando a realização de suas atividades.

10. Lopes, T., op cit.

11. Guimarães, L.; Aguilar, P.; Costa, T. “Aprendiz de feiticeiro e o duplo papel do teatro em um museu de ciências: A formação de plateia infantojuvenil com engajamento nas descobertas científicas". In: Congreso RedPOP 2015 Libro de Memorias. Medellin: Parque Explora e RedPOP, 1, pp 1786-1793. 2015.

12. Lopes, T. "Ciência em cena: discutindo ciência por meio do teatro". Presença Pedagógica, 6, 31. 2000.
13. Lopes, T. "O palco de Brecht e o céu de Galileu: tudo se move: teatro e ciência nas três versões dramáticas da peça Vida de Galileu, de Bertolt Brecht". Tese (mestrado em teatro) - Centro de Letras e Artes, Universidade do Rio de Janeiro, Rio de Janeiro, 2000.

14. Lopes, T. “Integrando a percepção de estudantes à criação de peça teatral: uma alternativa de educação científica em diálogo com as artes". Tese (doutorado) - Instituto Oswaldo Cruz, Pós-Graduação em Ensino em Biociências e Saúde, 2012.

15. Massarani, L. "Ciência, sociedade, câmera... ação!" In: Oliveira, B. J. (org.). História da ciência no cinema 2 - O retorno. Belo Horizonte: Aegumentum, Scientia UFMG. 2007. pp 131-143.

16. Reznik, G. "Imagem da ciência e de cientistas em curtas de animação". Dissertação (mestrado em história das ciências e das técnicas e epistemologia) - Universidade Federal do Rio de Janeiro, Rio de Janeiro, 2017.

17. Moreira, I. de C.; Massarani, L. "(En)canto científico: temas de ciência em letras da música popular brasileira". História, Ciências, Saúde-Manguinhos, 13, supl., pp 159-175. 2006.

18. Almeida, C.; Massarani, L.; Moreira, I. "Representations of science and technology in cordel literature". Bakhtiniana: Revista de Estudos do Discurso, 11, pp 5-25. 2016.

19. História, Ciências, Saúde-Manguinhos, 13, supl. (Diálogo entre ciência e arte), Rio de Janeiro, out. 2006.

20. Massarani, L. (org.) Memórias do Simpósio Ciência e Arte 2006. Rio de Janeiro: Fundação Oswaldo Cruz. 2007.

21. Rosseto, R. $O$ espectador e a relação do ensino do teatro com o teatro contemporâneo. Disponível em: http://www.fap.pr.gov.br/arquivos/ File/RevistaCientifica3/10_Robson_Rosseto.pdf. Acesso 1 set 2017.

22. Ferreira, T. A escola no teatro e o teatro na escola. $2^{\mathrm{a}}$ ed. Porto Alegre: Mediação. 2010.

23. De Marinis, M. En busca del actor y del espectador: compreender el teatro II. Buenos Aires: Galerna. 2005.

24. Desgranges, F. A pedagogia do espectador. São Paulo: Hucitec. 2003.

25. Martín-Barbero, J. "América Latina e os anos recentes: o estudo da recepção em comunicação social". In: De Sousa, M. W. (org.). Sujeito, o lado oculto do receptor. São Paulo: Brasiliense. 1995. pp 39-68.

26. Este trabalho não seria possível sem a contribuição das equipes envolvidas nas atividades analisadas em ambos os museus. Gostaríamos de agradecer especialmente à equipe do Ciência em Cena, do Museu da Vida, pela fundamental colaboração, em vários níveis, para a realização desta pesquisa. 